\title{
Connectivity and Topology Invariance in Self-Assembled and Halogen-Bonded Anionic $(6,3)$-Networks
}

\author{
Franck Meyer, Tullio Pilati, Konstantis F. Konidaris (D), Pierangelo Metrangolo \\ and Giuseppe Resnati *
}

Laboratory of Nanostructured Fluorinated Materials (NFMLab), Department of Chemistry, Materials, and Chemical Engineering “Giulio Natta”, Politecnico di Milano, Via L. Mancinelli 7, 20131 Milano, Italy; franck.meyer@ulb.ac.be (F.M.); tullio.pilati@gmail.com (T.P.); konstantis.konidaris@polimi.it (K.F.K.);

Pierangelo.metrangolo@polimi.it (P.M.)

* Correspondence: giuseppe.resnati@polimi.it; Tel.: +39-02-2399-3032 or +39-338-8719-492

Received: 24 October 2017; Accepted: 21 November 2017; Published: 24 November 2017

\begin{abstract}
We report here that the halogen bond driven self-assembly of 1,3,5-trifluorotriiodobenzene with tetraethylammonium and -phosphonium bromides affords 1:1 co-crystals, wherein the mutual induced fit of the triiodobenzene derivative and the bromide anions (halogen bond donor and acceptors, respectively) elicits the potential of these two tectons to function as tritopic modules $(6,3)$. Supramolecular anionic networks are present in the two co-crystals wherein the donor and the acceptor alternate at the vertexes of the hexagonal frames and cations are accommodated in the potential empty space encircled by the frames. The change of one component in a self-assembled multi-component co-crystal often results in a change in its supramolecular connectivity and topology. Our systems have the same supramolecular features of corresponding iodide analogues as the metric aspects seem to prevail over other aspects in controlling the self-assembly process.
\end{abstract}

Keywords: halogen bonding; supramolecular chemistry; crystal engineering; anion coordination

\section{Introduction}

Non-covalent intermolecular interactions hold a major role in the design of supramolecular assemblies and hence constitute a critical tool for crystal engineering [1]. Among the various intermolecular interactions, halogen bonding $(\mathrm{XB})$ has attracted considerable interest in recent years [2], and systems self-assembled under $\mathrm{XB}$ control have found applications in several areas, spanning biopharmacology [3-5], catalysis [6,7], and materials science [8-10]. XBs display similar characteristics with hydrogen bonds (HBs) in terms of their strength and high directionality [2].

$\mathrm{XB}$ directionality plays a particularly critical role in the design and synthesis of supramolecular systems as it translates tectons geometry into self-assembled architecture geometry [11,12]. For instance, when para-diiodotetrafluorobenzene, or its dibromo analogue, self-assemble with linear XB acceptors, e.g., 4,4'-dipyridyl, linear infinite chains are formed; when meta or ortho isomers are used, zig-zag infinite chains are obtained with angles along the chain close to $120^{\circ}$ and $60^{\circ}$, respectively [13-18]. Iodoaromatics are usually good XB donors and this is particularly true when the aromatic moiety bears electron withdrawing groups [2], and it can be expected that 1,3,5-trifluorotriiodobenzene (1) has a tendency to work as a tritopic $\mathrm{XB}$ donor after a trigonal geometry and to afford $(6,3)$ networks when interacting with bi- or tritopic acceptors $[19,20]$. A search in the Cambridge Structural Database (CSD) confirms that this may be the case [21-23]. On the other hand, calculations have shown that, as a consequence of the charge transfer component of the interaction [19], the XB donor ability of the iodine atoms of $\mathbf{1}$ decreases when the number of XBs the tecton (1) is already involved in is increased [20]. 
In other words, the formation of the third $\mathrm{XB}$ is energetically less favored than the second, and the formation of the second less favored than the first one [24]. Indeed, the number of XBs given by the $\mathrm{XB}$ donor 1 with usual acceptors (e.g., $\mathrm{N}$ atoms and anions) can be two or even one [25-27], and it has been argued that the preferential formation of infinite chains (1D nets) rather than honeycomb systems (2D nets) may also be associated with steric reasons, i.e., the problem to fill the potential empty space encircled by the hexagonal frame. Moreover, the number of XBs formed by a given acceptor on interaction with $\mathbf{1}$ may vary, e.g., if solvated co-crystals are formed [28,29]. Moreover, when a series of compositionally related co-crystals is obtained on assembly of $\mathbf{1}$ with a series of salts wherein the cation is the same and the anion changes, the number of XBs formed by the different anions may vary or remain unchanged and the same may happen for the topology of the obtained supramolecular anions [18,21]. For instance, $\mathbf{1}$ and tetra- $n$-butylammonium iodide [21], or bromide and chloride [30] give 2D systems wherein both the $\mathrm{XB}$ donor and acceptors are tritopic; however, when tetra- $n$-butylammonium thiocyanate is used [22], a 1D system is formed wherein $\mathbf{1}$ is tritopic and the anion either mono- or bitopic.

It thus seems that the connectivity and topology landscape of halogen bonded adducts given by the donor $\mathbf{1}$ is quite diversified and not easy to predict, and this is particularly true when anionic acceptors are used. We have already reported a series of adducts between $\mathbf{1}$ and iodide salts where both 1 and the iodide anion are tritopic and the systematic change of the cation showed that the cation size plays a major role in enabling the formation of $(6,3)$ networks [21]. It is required that cations fit in the cavity encircled by the hexagonal frames of the nets and the upper metric limit for the onium cation, enabling the $\mathrm{I} \cdots \mathrm{I}^{-}$supramolecular synthon to form $(6,3)$ networks that lie between the dimensions of tetra- $n$-propyl- and tetra- $n$-butylammonium cations. For instance, the self-assembly of $\mathbf{1}$ with $\mathrm{Et}_{4} \mathrm{~N}^{+} \mathrm{I}^{-}$ or $\mathrm{Et}_{4} \mathrm{P}^{+} \mathrm{I}^{-}(\mathbf{2} \mathbf{a}, \mathbf{b})$ affords co-crystals $\mathbf{3} \mathbf{a}, \mathbf{b}$ where both $\mathbf{1}$ and the iodide ions are tritopic and form $(6,3)$ networks where the two modules alternate at the network nodes (Scheme 1); the same happens with $n-\mathrm{Pr}_{4} \mathrm{~N}^{+} \mathrm{I}^{-}$but not with $n-\mathrm{Bu}_{4} \mathrm{~N}^{+} \mathrm{I}^{-}$.<smiles>Fc1c(I)c(F)c(I)c(F)c1I</smiles>

\section{$+\mathrm{Et}_{4} \mathrm{Pn}^{+} \mathrm{X}^{-}$}

$2 a-d$

1

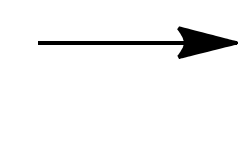

$\begin{array}{ccc} & \mathbf{P n} & \mathbf{X} \\ \text { a } & \mathbf{N} & \mathbf{I} \\ \text { b } & \mathbf{P} & \mathbf{I} \\ \text { C } & \mathbf{N} & \mathbf{B r} \\ \text { d } & \mathbf{P} & \mathbf{B r}\end{array}$

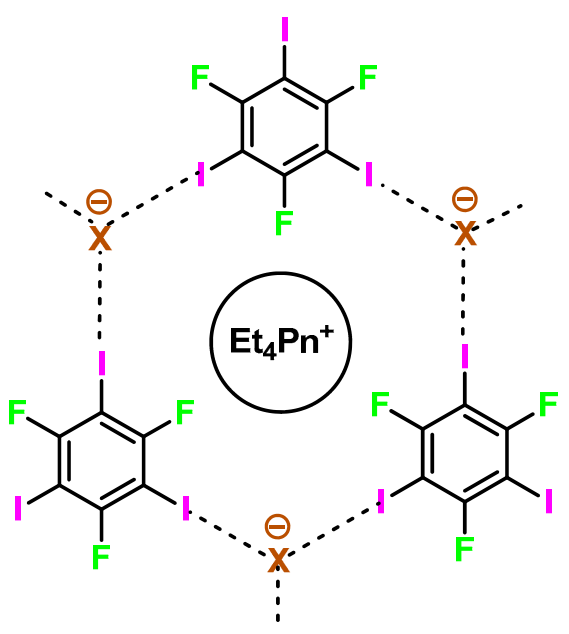

$3 a-d$

Scheme 1. The formation of the two species (i.e., iodobenzene derivative $\mathbf{1}$ and salts $\mathbf{2} \mathbf{a}-\mathbf{d}$ ) and three component (i.e., $\mathbf{1}$, the cation, and the anion from salts $\mathbf{2 a}-\mathbf{d}$ ) co-crystals $3 \mathbf{a}-\mathbf{d}$ via self-assembly of 1,3,5-trifluorotriiodobenzene (1) with onium halides $\mathbf{2 a - d}$.

As a part of an ongoing project aimed at changing the composition of multi-component and self-assembled systems, while maintaining unmodified their supramolecular characteristics [31], we were interested in identifying cases where the change of the anion in $\mathbf{3} \mathbf{a}, \mathbf{b}$ preserves all the supramolecular characteristics described above, and decided to co-crystallize 1 with $\mathrm{Et}_{4} \mathrm{~N}^{+} \mathrm{Br}^{-}$and $\mathrm{Et}_{4} \mathrm{P}^{+} \mathrm{Br}^{-}(\mathbf{2} \mathbf{c}, \mathbf{d})$ (Scheme 1). We reasoned that the formation of $(6,3)$ networks $\mathbf{3 c}, \mathbf{d}$ from $\mathbf{1}$ and $\mathbf{2 c}, \mathbf{d}$ is 
quite likely while the hexagonal frames having bromide anions at three of their vertexes should be smaller than analogous frames having iodide anions $\left(\mathrm{I} \cdots \mathrm{Br}^{-}\right.$bonds are typically shorter than $\mathrm{I}^{\cdots} \mathrm{I}^{-}$ bonds), the used onium cations would comfortably fit also in the smaller cavities formed by bromide anions as tetraethyl onium cation is safely below the cation upper size limit for the formation of $(6,3)$ nets based on the $\mathrm{I}_{\cdots} \mathrm{I}^{-}$supramolecular synthon. Here, we report that the connectivity and the topology in the adducts $\mathbf{3 c}, \mathbf{d}$ (afforded by $\mathbf{1}$ and $\mathbf{2} \mathbf{c}, \mathbf{d}$ ) is the same as in $\mathbf{3 a} \mathbf{a}, \mathbf{b}$ (Figure 1).

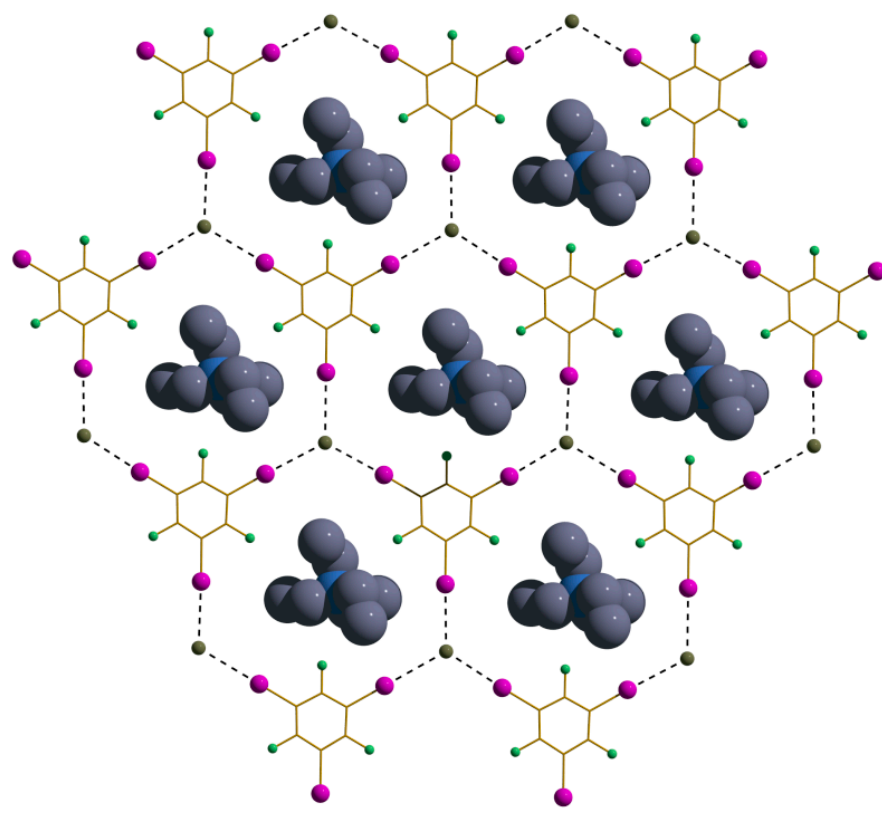

Figure 1. Partial representation of one honeycomb network of 3c. The $\mathrm{Et}_{4} \mathrm{~N}^{+}$cations, sitting at the center of the hexagonal cavities, are represented with space-filling models. The XBs are black dotted lines. Color code: C: grey; N: blue; I: purple; F: light green; Br: olive.

The number of XBs given by the donor $\mathbf{1}$ and by iodide and bromide acceptors remains unchanged in the four co-crystals $\mathbf{3 a - d}$, and the same holds for the topology of the respective supramolecular anions, as the contraction of the hexagonal frames size resulting from bromide for iodide substitution has been tolerated, and cations invariably sit in the hexagonal cavities.

\section{Results and Discussion}

Whitish crystalline solids $(3 \mathbf{c}, \mathbf{d})$ were obtained on slow evaporation at room temperature of equimolar solutions of $\mathbf{1}$ and tetraethylammonium or -phosphonium bromide (2c or $\mathbf{2 d}$, respectively) in $\mathrm{CH}_{2} \mathrm{Cl}_{2}$ /methanol mixtures. The melting points of these solids were quite sharp and in between those of starting compounds, suggesting that well-defined chemical species had been obtained rather than physical mixtures. IR spectra showed the presence of peaks of both $\mathrm{C}_{6} \mathrm{~F}_{3} \mathrm{I}_{3}$ and the onium moieties, only minor differences in peak intensities and wave numbers were observed with respect to pure starting compounds.

${ }^{1} \mathrm{H}$ and ${ }^{19} \mathrm{~F}$ NMR analyses in the presence of bis(2,2,2-trifluoroethyl) ether as internal standard for peaks integration [32] revealed that the starting compound ratio is $1: 1$.

Single crystals X-ray analyses of $\mathbf{3 c}, \mathbf{d}$ confirmed the starting compounds ratio established via the NMR technique and revealed that both compounds crystallize in the trigonal space group $R \overline{3} c \mathbf{1}$ and the bromide anions act as tritopic trigonal $\mathrm{XB}$ donors and acceptors, respectively, leading to $2 \mathrm{D}$ anionic networks with $(6,3)$ topology. The bromide ions and iodobenzene moiety 1 alternate at the nodes of the net and $\mathrm{Et}_{4} \mathrm{~N}^{+}$or $\mathrm{Et}_{4} \mathrm{P}^{+}$cations are accommodated in the center of the hexagonal space. 
Two different $\mathrm{I} \cdots \mathrm{Br}^{-}$contacts and $\mathrm{C}-\mathrm{I} \cdots \mathrm{Br}^{-}$angles are present in both $\mathbf{3 c}$ and $\mathbf{3 d}$, and the respective

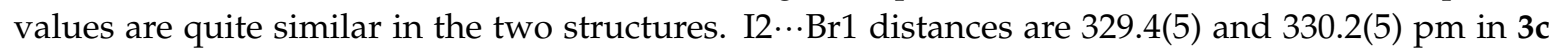
and 3d, respectively, while I1 $\cdots$ Br1 distances are slightly longer (341.6(3) and 343.8(4) pm). These values correspond to normalized contacts $\left(\mathrm{N}_{\mathrm{c}}\right)$ that are quite small [33] (they are in the range 0.84-0.87), suggesting that XBs in these structures are fairly strong. This is even more notable $[19,20]$ if we consider that the electron donor ability of the bromide and the electron acceptor ability of the iodofluorocarbon are split over three XBs. Consistent with this strength, the two different C-I $\cdots B$ Br angles present in $\mathbf{3 c}, \mathbf{d}$ are almost linear (they span in a value range of $\left.172.87(5)-179.88(5)^{\circ}\right)$. The hexagonal motifs of the $2 \mathrm{D}$ honeycomb networks are slightly distorted due to the deviation of the $\mathrm{I} \cdots \mathrm{Br}^{-} \cdots \mathrm{I}$ angles (they vary between $117.68(1)^{\circ}$ and $\left.124.62(1)^{\circ}\right)$ from the ideal $120^{\circ}$ for a symmetric trigonal coordination.

All these features nicely parallel those in corresponding nets formed by iodide anions and a comparison between the hexagonal frames of $\mathbf{3 c}$ and 3a (refcode CIZRUZ) [21] is depicted in Figure 2. The dimensions of the hexagonal cavities are estimated by the sides of the two triangles; one is connecting the naked $\mathrm{Br}^{-}$or I- ions and the other one the centroids of the phenyl rings of $\mathbf{1}$. Iodide anions are larger than bromide anions and $\mathrm{I} \cdots \mathrm{I}^{-}$halogen bonds are longer than the $\mathrm{I} \cdots \mathrm{Br}^{-}$ ones, resulting in hexagons with slightly greater dimensions in the iodide based nets. Despite this, the honeycomb topology is sustained, consistent with the fact that its formation is critically dependent on the cation's sitting in the internal space of the hexagonal frame and with the fact that the critical cation size was found between the dimensions of $n-\operatorname{Pr}_{4} \mathrm{~N}^{+}$and $n-\mathrm{Bu}_{4} \mathrm{~N}^{+}$in honeycomb nets formed by iodide anions. The ability of the hexagonal frames formed by bromide anions to nicely accommodate $\mathrm{Et}_{4} \mathrm{~N}^{+}$and $\mathrm{Et}_{4} \mathrm{P}^{+}$cations in $3 \mathbf{c}, \mathbf{d}$ is confirmed by the fact that the $2 \mathrm{D}$ supramolecular anions are quite flat (Figure 3), while they become undulated when the frame/cation mismatch forces the cations to protrude out of the hexagons [21].
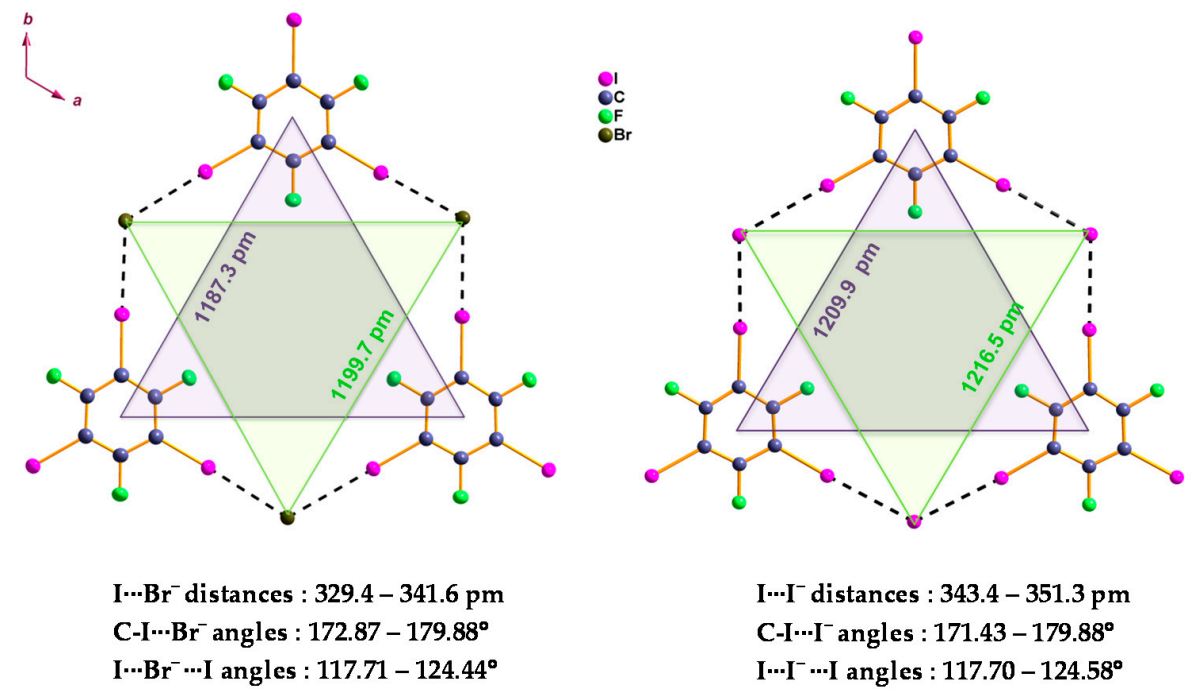

Figure 2. A view along the crystallographic $c$ axis of one hexagonal frame of $3 \mathbf{c}(\mathbf{l e f t})$ compared to the corresponding frame for 3a (right). Semi-transparent triangles connect the naked $\mathrm{Br}^{-}$or $\mathrm{I}^{-}$ions (greenish) and the centers of the phenyl rings of $\mathbf{1}$ (purple).

The cations' nature affects the distance between two adjacent anionic layers as well; specifically, the larger the cation is, i.e., the more it protrudes out of the hexagons, the greater the interlayer separation becomes [34]. The distance between the two adjacent layers is 437.0(1) pm in $3 \mathrm{c}$ and is slightly greater in $\mathbf{3 d}(458.5(1) \mathrm{pm})$. This trend has also been observed between $\mathbf{3 a}$ and $\mathbf{3 b}$ (interlayer separations are 452.9 and $460.1 \mathrm{pm}$, respectively) and is probably due to the fact that a phosphonium cation is larger than the corresponding ammonium cation. The interlayer separations in $3 \mathbf{c}, \mathbf{d}$ are smaller than the separation of the two supramolecular anionic nets in the co-crystal formed 
by the triiodobenzene derivative $\mathbf{1}$ with tetra- $n$-propylammonium iodide (554.9 pm), the largest tetraalkylammonium iodide that affords a honeycomb net upon self-assembly with $\mathbf{1}$.

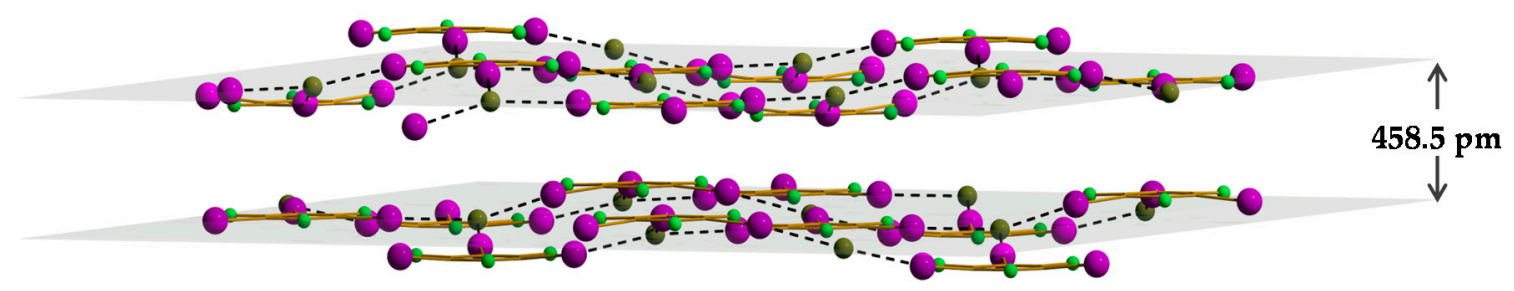

Figure 3. Two supramolecular anionic layers in the crystal structure of 3d. Semitransparent planes are the mean square planes through the anions of a layer. Color codes as in Figure 1; brown lines are the covalent bonds; black dotted lines are $\mathrm{XBs} ; \mathrm{Et}_{4} \mathrm{P}^{+}$cations have been omitted for clarity.

Short contacts exist between the fluorine atoms of $\mathbf{1}$ and the partially positive hydrogen atoms of the methylene groups bound to the nitrogen and phosphorous atoms of $\mathbf{3 c}, \mathbf{d}$ (Figure S1), and this suggests that onium cations potentially serve as templating agents for the formation of the hexagonal frames. These contacts can be considered as $\mathrm{C}-\mathrm{H} \cdots \mathrm{F}-\mathrm{C}$ hydrogen bonds and may play a role in assisting the self-assembly of the hexagonal anionic frames. This possibility is supported by the presence of similar HBs in related honeycomb nets [21]. The templating role of the cation is backed by the fact that, in the honeycomb network formed by triethyl-chloromethylammonium chloride [25], the XB donor 1 is pinned in its position by the $\mathrm{I} \cdots \mathrm{Cl}^{-}$XBs forming the supramolecular anion, by the $\mathrm{H} \cdots \mathrm{F} \mathrm{HBs}$ involving the "acidic" methylene groups, and by a further $\mathrm{XB}$ wherein the chlorine of the $\mathrm{N}^{+} \mathrm{CH}_{2} \mathrm{Cl}$ moiety is the $\mathrm{XB}$ donor and the belt of the iodine of $\mathbf{1}$ is the acceptor.

In order to confirm that metric aspects enable massive self-assembly of $\mathbf{1}$ and $\mathbf{3 c}$, $\mathbf{d}$ into honeycomb nets, powder X-ray diffraction (pXRD) analyses were carried out for 3c (Figure S5) and 3d (Figure 4). Experimental patterns nicely match patterns simulated from single crystal analyses, and phase purity of the crystallized compounds is thus proven.

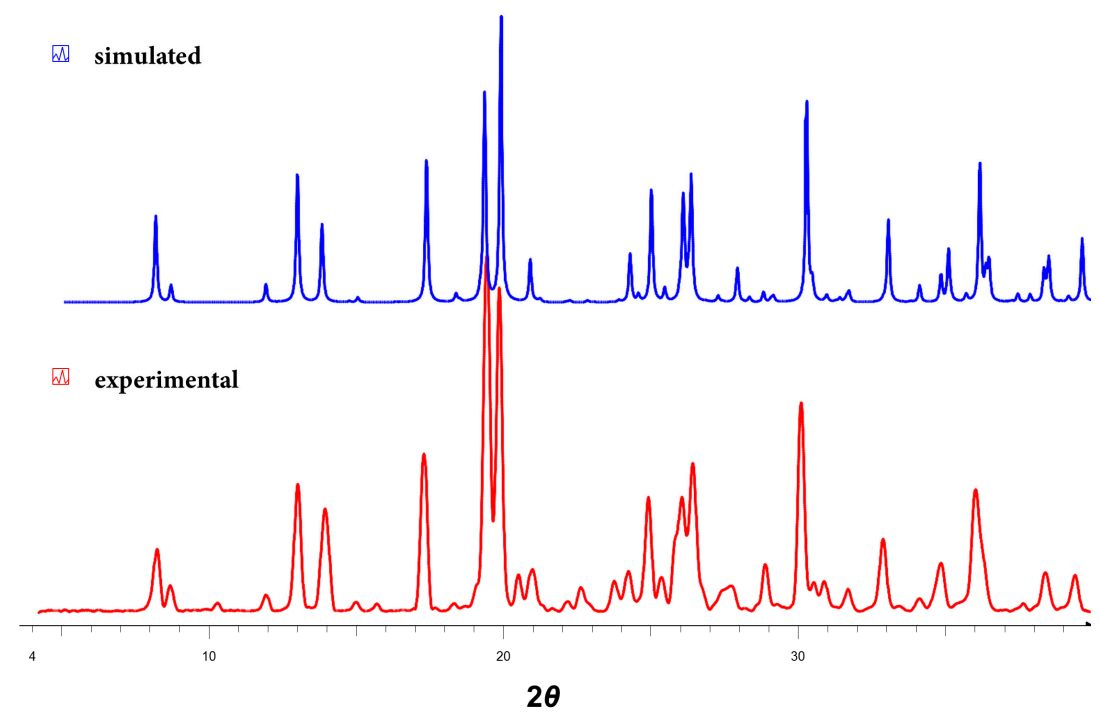

Figure 4. Powder X-ray Diffraction patterns of $\mathbf{3 d}$.

Finally, ${ }^{19} \mathrm{~F}$ NMR experiments were performed to assess the XB presence between $\mathbf{1}$ and $\mathbf{2 c}, \mathbf{d}$ in solution (Figure 5). Small upfield shifts were observed for the signal of $\mathbf{1}$ upon the addition of different onium salts, with the chemical shift changes ranging from 0.028 to $0.162 \mathrm{ppm}$ (Table S1). For a given 
cation, bromide salts afforded smaller chemical shift changes than iodide salts in all cases, consistent with observations reported for other haloperfluorocarbons/halide adducts in solution [35].

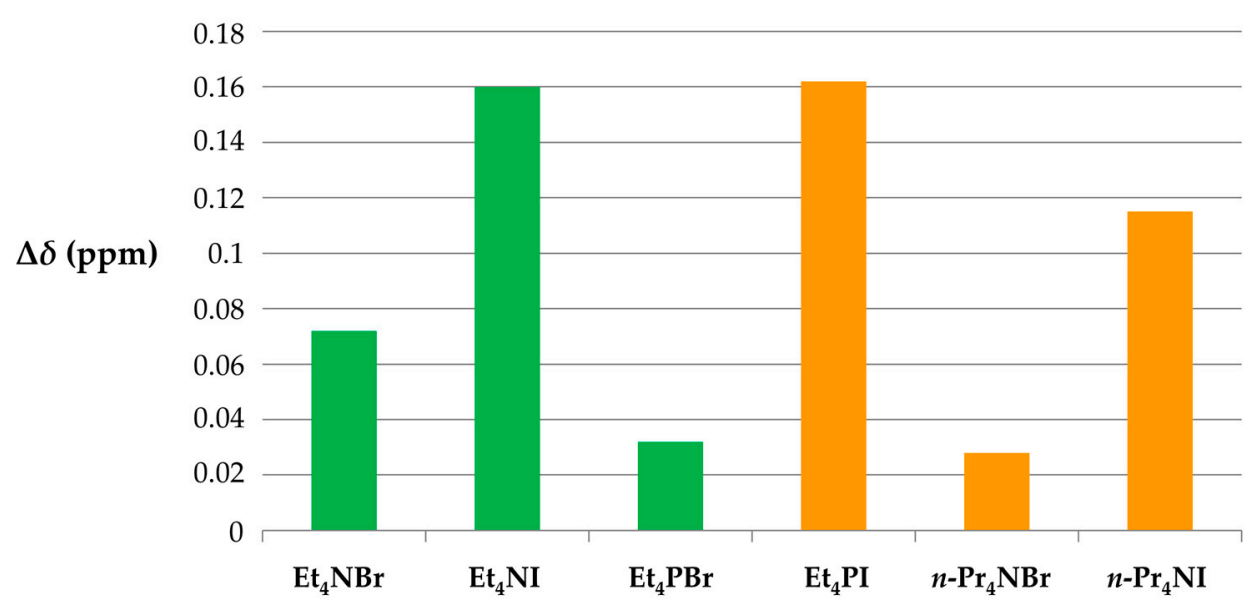

Figure 5. Variation of ${ }^{19} \mathrm{~F}$ NMR chemical shift of 1,3,5-triidotrifluorobenzene (1) upon interaction with some onium bromides and iodides when 10 equivalents of the onium salt was added to a $5 \mathrm{mM}$ solution of $\mathbf{1}$ in deuterochloroform.

\section{Materials and Methods}

\subsection{General Information}

The starting materials 1,3,5-trifluorobenzene, tetraethylammonium bromide, and tetraethylphosphonium bromide were purchased from Sigma-Aldrich and used without further purification. Melting points were determined on a Reichert instrument by observing the melting process through an optical microscope. ATR-FTIR spectra were obtained using a Nicolet Nexus FTIR spectrometer. Peaks frequencies, given in wave numbers, were rounded to $1 \mathrm{~cm}^{-1}$ using automatic peak assignment.

\subsection{Procedures and Compound Characterization}

\subsubsection{Preparation of 1,3,5-Triiodo-2,4,6-trifluorobenzene (1) [36]}

KI (7.14 g, $43.56 \mathrm{mmol})$ was added slowly to a stirred mixture of periodic acid ( $3.30 \mathrm{~g}, 14.50 \mathrm{mmol})$ in concentrated $\mathrm{H}_{2} \mathrm{SO}_{4}(20 \mathrm{~mL})$ at $0{ }^{\circ} \mathrm{C}$. The obtained dark mixture was cooled with an ice bath while 1,3,5-trifluorobenzene $(1.0 \mathrm{~mL}, 9.68 \mathrm{mmol})$ was added over $25 \mathrm{~min}$. The mixture was heated to $70{ }^{\circ} \mathrm{C}$ for $4 \mathrm{~h}$, then cooled to room temperature, poured on ice, and extracted with diethyl ether $(3 \times 50 \mathrm{~mL})$. The collected organic phases were washed with sat. $\mathrm{Na}_{2} \mathrm{~S}_{2} \mathrm{O}_{3}$ and water, then dried with $\mathrm{Na}_{2} \mathrm{SO}_{4}$. After evaporation of the solvent, 1 was recovered as a pure white powder in $80 \%$ yield. ${ }^{19} \mathrm{~F} \mathrm{NMR}$ $\left(\mathrm{CDCl}_{3}, 235 \mathrm{MHz}\right): \delta$-69.90 ppm; m.p.: 158-159 ${ }^{\circ} \mathrm{C}$; FT-IR $\left(\mathrm{KBr}\right.$ pellet, $\left.\mathrm{cm}^{-1}\right)$ : 1561, 1401, 1325, 1048, 704,652 .

\subsubsection{Preparation of Co-Crystal 3c}

Co-crystals of 3c were formed by dissolving equimolar amounts of 1,3,5-trifluorotriiodobenzene and tetraethylammonium bromide in a mixture of $\mathrm{CH}_{2} \mathrm{Cl}_{2} / \mathrm{MeOH}(1: 1)$ and after slow isothermal evaporation of the solvents at room temperature. m.p.: $240-242{ }^{\circ} \mathrm{C}$. FT-IR $\left(\mathrm{KBr}\right.$ pellet, $\left.\mathrm{cm}^{-1}\right)$ : 2982, $1563,1473,1458,1394,1184,1036,1005,794,709$. 


\subsubsection{Preparation of Co-Crystal 3d}

A procedure similar to that used for $3 \mathrm{c}$ was employed. m.p.: $238-241^{\circ} \mathrm{C}$. FT-IR (KBr pellet, $\left.\mathrm{cm}^{-1}\right)$ : $2905,1561,1458,1393,1331,1267,1036,779,709$.

\subsection{Single Crystal Structure Determination}

The single crystal X-ray diffraction measurement of the $\mathbf{3 c}, \mathbf{d}$ was conducted on a Bruker SMART APEX CCD area detector diffractometer, equipped with a Bruker KRYOFLEX low temperature device, graphite monochromator, Mo K $\alpha$ radiation $(\lambda=0.71069 \AA)$ at $123 \mathrm{~K}$. Cell refinement and data reduction were performed with a Bruker SAINT [37]. The structures were solved with SHELXS [38] and refined with SHELX-97 [38]; absorption correction was performed based on a multi-scan procedure using SADABS [37]. Further crystallographic details of the structures in this paper are reported in Table S2.

\section{4. ${ }^{19}$ F NMR Experiments}

${ }^{19} \mathrm{~F}$ NMR spectra were recorded on a Bruker ADV 500 spectrometer at $25^{\circ} \mathrm{C}, \mathrm{CDCl}_{3}$ was used as solvent and $\mathrm{CFCl}_{3}$ as internal standard. $\Delta \delta$ values reported in Figure 4 for ${ }^{19} \mathrm{~F}$ NMR chemical shift of 1,3,5-trifluorotriiodobenzene (1) were obtained upon the addition of 10 equivalents of the onium halides $\left(n-\mathrm{Pr}_{4} \mathrm{~N}^{+} \mathrm{Br}^{-}, \mathrm{Et}_{4} \mathrm{~N}^{+} \mathrm{Br}^{-}, \mathrm{Et}_{4} \mathrm{P}^{+} \mathrm{Br}^{-}, n-\mathrm{Pr}_{4} \mathrm{~N}^{+} \mathrm{I}^{-}, \mathrm{Et}_{4} \mathrm{~N}^{+} \mathrm{I}^{-}\right.$, and $\left.\mathrm{Et}_{4} \mathrm{P}^{+} \mathrm{I}^{-}\right)$to $5 \mathrm{mM}$ solutions of $\mathbf{1}$ in $\mathrm{CDCl}_{3}: \delta_{\mathrm{F}}\left(\mathrm{ppm}, 5 \mathrm{mM}\right.$ sol. of $\mathbf{1}$ in $\left.\mathrm{CDCl}_{3}\right)=-69.90 ; \Delta \delta_{\mathrm{F}}(\mathrm{ppm})=\delta_{5 \mathrm{mM}}-\delta_{5 \mathrm{mM} \mathbf{1}}+10$ eq. onium halide $)$.

\subsection{Powder X-ray Diffraction Analyses}

The crystalline powder material of co-crystals was packed on borosilicate glass slides and the data sets were collected on a Bruker D8 instrument at $293 \mathrm{~K}$. The measurements were made in Bragg-Brentano geometry using Johansson monochromator to produce pure $\mathrm{CuK} \alpha_{1}$ radiation $(1.5406 \AA ; 45 \mathrm{kV}, 30 \mathrm{~mA})$ and a step-scan technique in the $2 \theta$ range of $4-40^{\circ}$. The data were acquired from a spinning sample by an $X^{\prime}$ Celerator detector in continuous scanning mode with a step size of $0.0167^{\circ}$ using a sample dependently counting times of $90 \mathrm{~s}$ per step. The comparison of simulated and experimental PXRD pattern confirms the structural uniformity of bulk co-crystal powders.

\section{Conclusions}

In general, different halides can assemble different structures under control of electrostatic interactions, metal coordination, and HB [39], and the same holds when XB is the driving force of the self-assembly processes $[40,41]$. Different halides can present different coordination spheres, and bromide for iodide substitution in heteromeric multicomponent systems (3) is expected to give rise to XBs and electrostatic attraction between opposite ions (the two strongest interactions in co-crystals $3 \mathbf{a}-\mathbf{d}$ ) endowed with strengths that are quite different [42]. The triiodobenzene derivative $\mathbf{1}$ can work as a mono-, bi-, or tritopic XB donor [43], and bromide anions frequently function as di-, tri-, or tetratopic acceptors [44], but such anions can also present other XBs in their first coordination sphere, as they have been reported to act even as octatopic acceptors [45]. In the systems described here, the tetraethyl onium cations enable the assembly of three units of $\mathbf{1}$ around a bromide anion and combined matching, both at steric and electronic levels, of all the components of $\mathbf{3 a - d}$ allows $\mathbf{1}$ to work as a planar and trigonal tecton in the XB driven self-assembly of supramolecular halide networks. This behavior recalls the HB driven self-assembly processes wherein trimesic acid or 1,3,5-triazine derivatives function as planar and threefold tectons.

The supramolecular similarity of $\mathbf{3 a}-\mathbf{d}$ indicates that, metric requirements being fulfilled, the ability of $\mathbf{1}$ to function as a tritopic XB donor is robust enough to elicit the tritopic acceptor potential of bromide anions, to tolerate non-minor differences in the strength of interactions driving the co-crystals self-assembly, and to afford the honeycomb nets. The similarity of $\mathbf{3 a}-\mathbf{d}$ gives rise to further examples wherein the mutual induced fit among the different components of a heteromeric co-crystal elicits their respective ability to act as tritopic tectons and affords honeycomb nets, with 
either bromide or iodide anions at the nodes [21]. The use of this heuristic principle in the design of other multi-component systems assembly with the same topology but with different compositions is under study.

Supplementary Materials: The following are available online: CCDC 1576571 and 1576572 contain the supplementary crystallographic data for this paper. These data can be obtained free of charge via www.ccdc. cam.ac.uk/data_request/cif, or by emailing data_request@ccdc.cam.ac.uk, or by contacting The Cambridge Crystallographic Data Centre, 12, Union Road, Cambridge CB2 1EZ, UK; fax: +44 1223336033.

Acknowledgments: KFK gratefully acknowledges the Politecnico di Milano for a Polimi International Fellowship (PIF).

Author Contributions: F.M. performed the experiments; T.P. collected X-ray data, and solved and refined the reported structures; K.F.K. wrote the paper and performed part of the experiments; P.M. conceived and designed the experiments; G.R. conceived and designed the experiments and wrote the paper.

Conflicts of Interest: The authors declare no conflict of interest.

\section{References and Notes}

1. Desiraju, G.R. Crystal engineering: From molecule to crystal. J. Am. Chem. Soc. 2013, 135, 9952-9967. [CrossRef] [PubMed]

2. Cavallo, G.; Metrangolo, P.; Milani, R.; Pilati, T.; Priimagi, A.; Resnati, G.; Terraneo, G. Halogen bonding. Chem. Rev. 2016, 115, 2478-2601. [CrossRef] [PubMed]

3. Ho, P.S. Biomolecular halogen bonds. Top. Curr. Chem. 2014, 358, 241-276.

4. Parisini, E.; Metrangolo, P.; Pilati, T.; Resnati, G.; Terraneo, G. Halogen bonding in halocarbon-protein complexes: A structural survey. Chem. Soc. Rev. 2011, 40, 2267-2278. [CrossRef] [PubMed]

5. Hardegger, L.A.; Kuhn, B.; Spinnler, B.; Anselm, L.; Ecabert, R.; Stihle, M.; Gsell, B.; Thoma, R.; Diez, J.; Benz, J.; et al. Systematic investigation of halogen bonding in protein-ligand interactions. Angew. Chem. Int. Ed. 2011, 50, 314-318. [CrossRef] [PubMed]

6. Jiang, S.; Zhang, L.; Cui, D.; Yao, Z.; Gao, B.; Lin, J.; Wei, D. The Important Role of Halogen Bond in Substrate Selectivity of Enzymatic Catalysis. Sci. Rep. 2016, 6, 34750. [CrossRef] [PubMed]

7. Bulfield, D.; Huber, S.M. Halogen Bonding in Organic Synthesis and Organocatalysis. Chem. Eur. J. 2016, 22, 14434-14450. [CrossRef] [PubMed]

8. Gazzera, L.; Milani, R.; Pirrie, L.; Schmutz, M.; Blanck, C.; Resnati, G.; Metrangolo, P.; Krafft, M.P. Design of highly stable echogenic microbubbles through controlled assembly of their hydrophobin shell. Angew. Chem. Int. Ed. 2016, 55, 10263-10267. [CrossRef] [PubMed]

9. Bolton, O.; Lee, K.; Kim, H.-J.; Lin, K.Y.; Kim, J. Activating efficient phosphorescence from purely organic materials by crystal design. Nat. Chem. 2011, 3, 205-210. [CrossRef] [PubMed]

10. Berger, G.; Soubhye, J.; Meyer, F. Halogen bonding in polymer science: From crystal engineering to functional supramolecular polymers and materials. Polym. Chem. 2015, 6, 3559-3580. [CrossRef]

11. Saccone, M.; Cavallo, G.; Metrangolo, P.; Pace, A.; Pibiri, I.; Pilati, T.; Resnati, G.; Terraneo, G. Halogen bond directionality translates tecton geometry into self-assembled architecture geometry. CrystEngComm 2013, 15, 3102-3105. [CrossRef]

12. De Santis, A.; Forni, A.; Liantonio, R.; Metrangolo, P.; Pilati, T.; Resnati, G. N ‥Br halogen bonding: 1D infinite chains through the self-assembly of dibromotetrafluorobenzenes with dipyridyl derivatives. Chem. Eur. J. 2003, 9, 3974-3983. [CrossRef] [PubMed]

13. Cinĉić, D.; Friŝĉić, T.; Jones, W. Experimental and database studies of three-centered halogen bonds with bifurcated acceptors present in molecular crystals, cocrystals and salts. CrystEngComm 2011, 13, 3224-3231. [CrossRef]

14. Liantonio, R.; Metrangolo, P.; Pilati, T.; Resnati, G. 4,4'-bipyridine 1,2-diiodo-3,4,5,6-tetrafluorobenzene. Acta Cryst. 2002, E58, o575-o577. [CrossRef]

15. Metrangolo, P.; Meyer, F.; Pilati, T.; Resnati, G.; Terraneo, G. 4,4'-bipyridine-2,4,5,6-tetrafluoro-1,3diiodobenzene (1/1). Acta Cryst. 2007, E63, o4243. [CrossRef]

16. Cinĉić, D.; Friŝĉić, T.; Jones, W. Isostructural materials achieved by using structurally equivalent donors and acceptors in halogen-bonded cocrystals. Chem. Eur. J. 2008, 14, 747-753. [CrossRef] [PubMed] 
17. Walsh, R.B.; Padgett, C.W.; Metrangolo, P.; Resnati, G.; Hanks, T.W.; Pennington, W.T. Crystal engineering through halogen bonding: Complexes of nitrogen heterocycles with organic iodides. Cryst. Growth Des. 2001, 1, 165-175. [CrossRef]

18. Cavallo, G.; Biella, S.; Lü, J.; Metrangolo, P.; Pilati, T.; Resnati, G.; Terraneo, G. Halide anion-templated assembly of di- and triiodoperfluorobenzenes into 2D and 3D supramolecular networks. J. Fluorine Chem. 2010, 131, 1165-1172. [CrossRef]

19. Roper, L.C.; Präsang, C.; Kozhevnikov, V.N.; Whitwood, A.C.; Karadakov, P.B.; Bruce, D.W. Experimental and theoretical study of halogen-bonded complexes of DMAP with di- and triiodofluorobenzenes. A complex with a very short N...I halogen bond. Cryst. Growth Des. 2010, 10, 3710-3720. [CrossRef]

20. Lucassen, A.C.B.; Karton, A.; Leitus, G.; Shimon, L.J.W.; Martin, J.M.L.; van der Boom, M.E. Co-crystallization of sym-triiodo-trifluorobenzene with bipyridyl donors: Consistent formation of two instead of anticipated three N...I halogen bonds. Cryst. Growth Des. 2007, 7, 386-392. [CrossRef]

21. Metrangolo, P.; Meyer, F.; Pilati, T.; Resnati, G.; Terraneo, G. Mutual induced coordination in halogen-bonded anionic assemblies with $(6,3)$ cation-templated topologies. Chem. Commun. 2008, 1635-1637. [CrossRef] [PubMed]

22. Cauliez, P.; Polo, V.; Roisnel, T.; Llusar, R.; Fourmigué, M. The thiocyanate anion as a polydentate halogen bond acceptor. CrystEngComm 2010, 12, 558-566. [CrossRef]

23. Jeon, I.-R.; Mathonière, C.; Clérac, R.; Rouzières, M.; Jeannin, O.; Trzop, E.; Collet, E.; Fourmigué, M. Photoinduced reversible spin-state switching of an Fe(III) complex assisted by a halogen-bonded supramolecular network. Chem. Commun. 2017, 53, 10283-10286. [CrossRef] [PubMed]

24. Berger, G.; Roeben, K.; Soubhye, J.; Wintjens, R.; Meyer, F. Halogen bonding in multi-connected 1,2,2-triiodoalkene involving geminal and/or vicinal iodines: A crystallographic and DFT study. CrystEngComm 2016, 18, 683-690. [CrossRef]

25. Pfrunder, M.C.; Micallef, A.S.; Rintoul, L.; Arnold, D.P.; Davy, K.J.P.; McMurtrie, J. Exploitation of the Menshutkin reaction for the controlled assembly of halogen bonded architectures incorporating 1,2-diiodotetrafluorobenzene and 1,3,5-triiodotrifluorobenzene. Cryst. Growth Des. 2012, 12, 714-724. [CrossRef]

26. Jeon, I.-R.; Jeannin, O.; Clerac, R.; Rouzieres, M.; Fourmigue, M. Spin-state modulation of molecular Fe(III) complexes via inclusion in halogen-bonded supramolecular networks. Chem. Commun. 2017, 53, 4989-4992. [CrossRef] [PubMed]

27. Aakeröy, C.B.; Wijethunga, T.K.; Desper, J. Practical crystal engineering using halogen bonding: A hierarchy based on calculated molecular electrostatic potential surfaces. J. Mol. Struct. 2014, 1072, 20-27. [CrossRef]

28. Raffo, P.A.; Cukiernik, F.D.; Baggio, R.F. The three-component cocrystal 1,3,5-trifluoro-2,4,6-triiododbenzene-pyridine $N$-oxide-water $(1 / 2 / 1)$ built up by halogen bonds, hydrogen bonds and $\pi-\pi$ interactions. Acta Cryst. 2015, C71, 84-88.

29. Aakeröy, C.B.; Wijethunga, T.K.; Desper, J. Constructing molecular polygons using halogen bonding and bifurcated N-oxides. CrystEngComm 2014, 16, 28-31. [CrossRef]

30. Triguero, S.; Llusar, R.; Polo, V.; Fourmigué, M. Halogen bonding interactions of sym-triiodotrifluorobenzene with halide anions: A combined structural and theoretical study. Cryst. Growth Des. 2008, 8, 2241-2247. [CrossRef]

31. Kumar, V.; Pilati, T.; Terraneo, G.; Meyer, F.; Metrangolo, P.; Resnati, G. Halogen bonded Borromean networks by design: Topology invariance and metric tuning in a library of multi component systems. Chem. Sci. 2017, 8, 1801-1810. [CrossRef] [PubMed]

32. Cardillo, P.; Corradi, E.; Lunghi, A.; Meille, S.V.; Messina, M.T.; Metrangolo, P.; Resnati, G. The N...I intermolecular interaction as a general protocol in the formation of perfluorocarbon-hydrocarbon supramolecular architectures. Tetrahedron 2000, 56, 5535-5550. [CrossRef]

33. The normalized contact $N_{c}$ is defined as the ratio $D_{X Y} /\left(r_{X}+r_{Y}\right)$, where $D_{X Y}$ is the experimental distance between the halogen bonded iodine atoms $X$ and halide anions $Y$ and $r_{X}$ and $r_{Y}$ are the van der Waals radius for iodine and the Pauling ionic radius of the halide anion $Y$, respectively. $N_{c}$ is a useful indicator of the relative interaction strength, more useful than the $\mathrm{XB}$ distance itself, because it allows distances between different interacting sites to be meaningfully compared.

34. The interlayer distance is calculated as the distance between the mean square planes passing through the anions of two adjacent layers. 
35. Liantonio, R.; Metrangolo, P.; Pilati, T.; Resnati, G. Fluorous interpenetrated layers in a three-component crystal matrix. Cryst. Growth Des. 2003, 3, 355-361. [CrossRef]

36. Wenk, H.H.; Sander, W. Generation of fluorinated m-benzyne derivatives in neon matrices. Eur. J. Org. Chem. 2002, 3927-3935. [CrossRef]

37. Bruker. SMART, SAINT and SADABS; Bruker AXS Inc.: Madison, WI, USA, 1999.

38. Sheldrick, G.M. Crystal structure refinement with SHELXL. Acta Cryst. 2015, C71, 3-8.

39. White, N.G.; MacLachlan, M.J. Anion-templated hexagonal nanotubes. Chem. Sci. 2015, 6, 6245-6249. [CrossRef]

40. Mercurio, J.M.; Knighton, R.C.; Cookson, J.; Beer, P.D. Halotriazolium axle functionalized [2]rotaxanes for anion recognition: Investigating the effects of halogen-bond donor and preorganization. Chem. Eur. J. 2014, 20, 11740-11749. [CrossRef] [PubMed]

41. Langton, M.J.; Robinson, S.W.; Marques, I.; Félix, V.; Beer, P.D. Halogen bonding in water results in enhanced anion recognition in acyclic and rotaxane hosts. Nat. Chem. 2014, 6, 1039-1043. [CrossRef] [PubMed]

42. Walsh, R.D.; Smith, J.M.; Hanks, T.W.; Pennington, W.T. Computational and Crystallographic Studies of Pseudo-Polyhalides. Cryst. Growth Des. 2012, 12, 2759-2768. [CrossRef]

43. Ding, X.H.; Ou, C.J.; Wang, S.; Xie, L.H.; Lin, J.Y.; Wang, J.P.; Huang, W. Co-crystallization of 1,3,5-trifluoro2,4,6-triiodobenzene (1,3,5-TFTIB) with a variety of Lewis bases through halogen-bonding interactions. CrystEngComm 2017, 19, 5504-5521. [CrossRef]

44. Metrangolo, P.; Pilati, T.; Terraneo, G.; Biella, S.; Resnati, G. Anion coordination and anion-templated assembly under halogen bonding control. CrystEngComm 2009, 11, 1187-1196. [CrossRef]

45. Lindeman, S.V.; Hecht, J.; Kochi, J.K. The Charge-transfer motif in crystal engineering. Self-assembly of acentric (diamondoid) networks from halide salts and carbon tetrabromide as electron-donor/acceptor synthons. J. Am. Chem. Soc. 2003, 125, 11597-11606. [CrossRef] [PubMed]

Sample Availability: Samples of the compounds are not available from the authors.

(C) 2017 by the authors. Licensee MDPI, Basel, Switzerland. This article is an open access article distributed under the terms and conditions of the Creative Commons Attribution (CC BY) license (http://creativecommons.org/licenses/by/4.0/). 